\title{
Do Génio ao Jogo. O papel da Técnica na Transformaçáo dos Valores Estéticos em Walter BENJAMIN
}

Nélio Rodrigues Conceição ${ }^{1}$

\begin{abstract}
Resumo: Analisando o papel desempenhado pela questâo da técnica no pensamento de Walter Benjamin, o artigo debruça-se sobre a transformação dos valores estéticos, na modernidade. As técnicas de reprodução/registo inventadas nos séculos XIX e XX, como a fotografia e o cinema, obrigaram a uma revisão das articulaçôes entre arte, técnica e história, articulaçôes que Benjamin desenvolveu em diversos sentidos. Contudo, não encontramos, nos seus textos, uma filosofia da técnica de princípios claramente estabelecidos. Portanto, o presente artigo visa estabelecer uma constelação de temas, os quais, brotando dos seus textos, nos permitem clarificar como a técnica influencia a transformaçáo e a criação de valores estéticos, sendo estes entendidos como eixos em torno dos quais se dão a produção e a crítica dos fenómenos estéticos. A fotografia, constituindo um momento de viragem incisivamente estudado pelo autor, é o fio condutor das diferentes leituras. Historicidade da percepção; dimensão política da arte; sua relaçáo com a memória; elemento de jogo: sấo estes os quatro eixos em torno dos quais se procura clarificar e, sempre que possível, prolongar a proposta benjaminiana.
\end{abstract}

Palavras-Chave: Técnica. História. Política. Memória. Jogo.

\section{ARTE, TÉCNICA E HiSTÓRIA}

Walter Benjamin foi um dos primeiros autores a debruçar-se sobre as implicações do advento das técnicas de registo/reprodução, tais como a fotografia ou o cinema, para a compreensão das transformaçóes artísticas, na modernidade. Contudo, essa atenção não desembocou numa filosofia da técnica, de princípios claramente estabelecidos, mas sim num conjunto de textos, ou de observaçóes pontuais, que incidem quase sempre em objectos de estudo concretos e em situações históricas particulares. Neste sentido, o presente artigo propóe-se elaborar uma constelaçáo de temas que, extraídos dos seus textos, nos permitem clarificar o papel da técnica na transformação e criação de valores estéticos, sendo estes entendidos como eixos em torno dos quais circulam a produção e a crítica dos fenómenos estéticos. Essa

\footnotetext{
${ }^{1}$ Doutorado em Filosofia - Estética, pela Faculdade de Ciências Sociais e Humanas da Universidade Nova de Lisboa, em 2013. Actualmente, é pesquisador integrado, com uma bolsa de pós-doutoramento da Fundação para a Ciência e Tecnologia, no IFILNOVA - Instituto de Filosofia da Nova. E-mail: alnelio@yahoo.com
}

http://dx.doi.org/10.1590/S0101-31732017000100005 
clarificação é importante para melhor compreender a leitura que Benjamin faz da modernidade e, consequentemente, para melhor compreender elementos fundamentais da estética que nos é contemporânea.

As análises de Benjamin, partindo de um ponto de vista histórico, exploram os fenómenos artísticos na sua complexidade intrínseca. Em "Sobre alguns motivos na obra de Baudelaire", texto publicado em 1940, Benjamin refere que Baudelaire introduziu a experiência do choque no âmago do seu trabalho artístico (BENJAMIN, 2006a, p. 112-113). O efeito de choque, intimamente ligado a alteraçôes sensoriais e ao fenómeno da multidão urbana, relaciona-se também com a fotografia, pois esta, ao fixar um acontecimento por tempo ilimitado, aplica um choque ao momento captado, tornando-o póstumo. Essa ideia aparece no contexto de uma reflexão sobre os pequenos gestos que desencadeiam um processo complexo composto por uma série de momentos, implicando novas experiências tácteis e ópticas que exigem ao homem um constante exercício de adaptação: "[...] a técnica foi submetendo o sistema sensorial humano a um treino [Training] complexo." (BENJAMIN, 2006a, p. 127). Já no ensaio "Pequena história da fotografia”, publicado em 1931, Benjamin associa um progresso técnico - a diminuição do tamanho das câmaras e a crescente possibilidade de fixar imagens fugidias e secretas - ao choque que "[...] faz parar no observador os mecanismos associativos." (BENJAMIN, 2006c, p. 261). Nas várias versôes do texto "A obra de arte na época da sua reprodutibilidade técnica", escritas ao longo da década de 30, o choque é estendido à compreensão dos efeitos do dadaísmo e do cinema. Neste sentido, e voltando à leitura de Baudelaire, vemos que a ideia do efeito de choque, na sua transversalidade, percorre os aspectos mais estritamente poéticos, as novas técnicas, mas também os elementos sensoriais e psicológicos (Freud - e a questão do trauma - é, nesse contexto, uma referência importante, permitindo um aprofundamento da relação entre memória, lembrança e consciência). O pano de fundo é aqui, como em outros textos, uma reflexão histórico-crítica sobre as condiçóes da experiência, na modernidade.

A questão da técnica constitui igualmente uma boa pedra-de-toque do materialismo histórico de Benjamin, o qual, embora dialogue com o marxismo, não se confunde com qualquer ortodoxia, afastando-se também, em aspectos determinantes, das concepçóes materialistas de autores que com ele dialogaram directamente, como Adorno e Horkheimer. $\mathrm{Na}$ 
verdade, o materialismo benjaminiano vai beber em fontes táo distantes quanto as de Leibniz ou Goethe. ${ }^{2}$

O texto "Eduard Fuchs, coleccionador e historiador", escrito a pedido de Horkheimer, para publicação na Revista de Investigação Social, constitui, paralelamente às entradas de Das Passagen-Werk, reunidas sob a letra $\mathrm{N}$, e a "Sobre o Conceito de História", uma das mais detalhadas exposiçôes da tarefa do materialista histórico. Nesse texto, Benjamin desenvolve algumas consideraçóes que, embora incidindo sobre o século XIX, permitem compreender de um modo mais amplo o seu interesse pelos fenómenos técnicos. Essas consideraçóes aparecem no contexto de uma crítica a um processo característico do século XIX, o da "desastrosa recepção da técnica", processo sustentado por uma série de ensaios entusiásticos (BENJAMIN, 2010, p. 116). A técnica obriga-nos a testar, a pôr em causa a separação positivista, e não dialéctica, entre ciências da natureza e ciências do espírito. "A técnica não é uma pura manifestação das ciências da natureza, é também uma manifestação histórica." (BENJAMIN, 2010, p. 116). O falhanço do positivismo prende-se com o facto de não ter sido capaz de perceber que a evolução da técnica está intimamente ligada à produção de mercadorias e é decisivamente determinada pelo capitalismo. E, do ponto de vista social, escapa-lhe o elemento destrutivo que a análise dialéctica é capaz de revelar, razão pela qual é necessário levar a sério a constituição histórica da técnica, resgatando-a das narrativas orientadas pelo ideal de progresso. O que significa: abrir a possibilidade de arrancar os seus objectos ao contínuo da história, salientando, por exemplo, o modo como as suas energias podem ser destrutivas - energias reclamadas pela guerra e pela sua preparação propagandística (BENJAMIN, 2010, p. 117).

Benjamin dirige seguidamente as suas críticas à história da cultura - à possibilidade de que o materialismo histórico seja visto como uma história da cultura -, fazendo notar que a distância a partir da qual esta apresenta os seus conteúdos assenta na ilusão e na falsa consciência. Tal distância é olhada com reserva pelo materialista histórico, pois, perante os génios e as suas criaçóes

\footnotetext{
2 Sobre a distinção entre os "métodos dialécticos" de Benjamin e Adorno, cf. Agamben, O Príncipe e o Sapo. O problema do método em Adorno e Benjamin (AGAMBEN, 2014, p. 127-147). Agamben ressalta, com razão, a importância da noção de mónada. Sobre a influência de Goethe, seria necessário explorar todas as implicaçôes da entrada [N2a, 4] de Das Passagen-Werk (BENJAMIN, 1991, V.1, p. 577), referente à equivalência entre o Urphänomen (fenómeno originário) goethiano e o conceito de Ursprung (origem) benjaminiano, tal como aparece inicialmente tematizado no "Prólogo Epistemológico-Crítico" de A origem do drama barroco alemão, equivalência que implica, todavia, uma transposiçáo dos domínios da natureza para os domínios da história.
} 
artísticas e científicas, facilmente é esquecida a escravidão anónima dos seus contemporâneos. Daí a célebre fórmula: "Não há documento de cultura que não seja também documento de barbárie.” (BENJAMIN, 2010, p. 118). Só falsamente a história da cultura pode ser considerada dialéctica. Por um lado, falta-lhe o momento destrutivo assegurado pelo pensamento dialéctico (interrupção do contínuo histórico); por outro lado, falta-lhe a autenticidade da experiência do historiador dialéctico. "Aumenta com certeza o peso dos tesouros que se acumulam sobre os ombros da humanidade. Mas não lhe dá forças para sacudi-los, e assim ficar com eles na mão." (BENJAMIN, 2010, p. 119). Apesar de todas as críticas dirigidas a Fuchs, Benjamin elogia-o por ter sido capaz de sacudir os princípios da história da cultura, aproximando-se da tarefa dialéctica. Impulsionado pelo seu carácter de coleccionador, entrou por zonas de fronteira, onde os conceitos tradicionais da arte já só podiam falhar. A “[...] escala de valores que antes determinara a relação com a obra de arte, no tempo de Winckelmann ou Goethe, perdeu toda a sua influência no caso de Fuchs." (BENJAMIN, 2010, p. 120).

Nesse contexto, Benjamin enuncia os elementos dialécticos da obra de Fuchs, isto é, os elementos que a aproximam de uma ciência histórica capaz de entender o seu objecto, não como uma simples acumulação de facticidade, mas como uma apreensão de um conjunto determinado de fios que representam a penetração de um passado na textura de um presente. Essa penetração não se rege por um nexo causal, nem o objecto histórico interessa pela "homenagem celebratória" que se lhe possa prestar; na sua relação ao presente, ele constituise na exacta tarefa dialéctica que tem de resolver. E essa tarefa conhece em Fuchs três momentos: interpretação da iconografia, significado da arte de massas, estudo das técnicas de reprodução. Enquanto objecto de estudo, as técnicas de reprodução introduzem um elemento destrutivo quanto às formas tradicionais de entender a arte. Ao lado da interpretação iconográfica e da acentuação da arte de massas, o estudo das técnicas de reprodução acentua a importância da recepção. São ainda corrigidos, dentro de certos limites: o processo de reificação a que está sujeita a obra de arte; o conceito de génio (“[...] a necessidade de não esquecer, para lá da inspiração, que tem o seu papel no nascimento da obra, a sua execuçáo, sem a qual ela não se tornará produtiva”); os abusos para que facilmente tende todo o formalismo (BENJAMIN, 2010, p. $120-121) .^{3}$

\footnotetext{
${ }^{3}$ Num dos fragmentos recolhidos no sexto volume de Gesammelte Schriften, Walter Benjamin escreve algo que vai ao encontro dessas constataçōes: "O questionamento sobre a técnica liquida a infrutífera alternativa entre forma e conteúdo.” (BENJAMIN, 1991, VI, p. 183). Essa mesma ideia aparece no
} 
Podemos extrapolar essas consideraçôes para o âmbito da crítica e da história da recepção de outros objectos de estudo, sejam eles provenientes da literatura, sejam da fotografia ou, mais recentemente, da arte digital. É importante referir que as ideias levantadas por Benjamin a propósito da técnica estão longe de se deixar esgotar pela questão da reprodução/reprodutibilidade das obras de arte, questão que guia um dos seus ensaios mais conhecidos e discutidos. O núcleo original da articulação entre arte, técnica e história tem sobretudo a ver com um modelo de pensamento capaz de pesar os processos de transformação, os elementos destrutivos e a relação dialéctica entre um Agora e um Outrora. Como veremos mais adiante, esse núcleo é desdobrado em diversos textos, que nem sempre comunicam entre si, mas que nos permitem abrir férteis pistas de leitura, quer quanto ao pensamento de Benjamin, quer quanto às implicaçôes da técnica nos nossos dias.

\section{O PRIVILÉGIO DA FOTOGRAFIA}

Se nos concentrarmos na técnica fotográfica, obteremos um ponto de vista privilegiado para a observação da relação entre arte, técnica e história, observação que implica, por sua vez, uma ponderação da transformação dos valores estéticos na modernidade. Por via da fotografia, essa transformação constitui, antes de mais, um alargamento dos meios técnicos que, directa ou indirectamente, interferem nas práticas artísticas, mas pressupóe também a propagação de novos conceitos e de novas formas de conceber a imagem. Para Benjamin, a relevância da fotografia para a arte tem pouco a ver com a questão: "quando é que uma fotografia é uma obra de arte?" Trata-se, mais essencialmente, de ir ao encontro de outra questão: "o que é que a fotografia faz à arte?” E isso envolve um elemento da fotografia que resiste às intençóes artísticas e esteticizantes, "[...] qualquer coisa [...] que continua a ser real hoje e nunca quererá ser reduzida a 'arte'." (BENJAMIN, 2006c, p. 246). Como destaca Sigrid Weigel, não entender esse "princípio metodológico" é passar completamente ao lado da originalidade e fertilidade do pensamento de Benjamin acerca da fotografia e da imagem (WEIGEL, 2013, p. 240). As respostas à questão "o que é que a fotografia faz à arte?" prolongam-se em pelo menos dois sentidos. O primeiro, o qual Benjamin entreviu de forma lapidar e que constitui uma das mais exploradas - e talvez das mais exíguas -

texto "O Autor como Produtor", no quadro de uma reflexão sobre a relação que o escritor mantém com a sua técnica, a qual constitui o elemento preponderante, quer da inscriçãa na ordem social que lhe é contemporânea, quer da dimensão política da sua produção. 
portas de entradas do seu pensamento, relaciona-se com a reprodutibilidade técnica das obras de arte. O segundo, mais subtil e que só aparentemente entra em contradição com o que acima foi destacado, relaciona-se com o modo específico como as técnicas, as práticas e os conceitos da fotografia contaminaram o mundo artístico. Por outras palavras, novos valores estéticos entraram em circulação.

O facto de a fotografia ter adquirido um lugar de relevo na arte contemporânea atesta a pertinência e a complexidade deste segundo aspecto. Um livro recente de Michael Fried, Why photography matters as art as never before, procura exactamente compreender as razóes que levaram a fotografia a alcançar esse lugar de relevo. Partindo da análise de diversos trabalhos fotográficos, embora desembocando na contemporaneidade, essa obra tem um pano de fundo filosófico (ou ontológico, como Fried por vezes defende), o qual, operando com noçôes desenvolvidas anteriormente pelo autor, como objectualidade e antiteatralidade, lhe dá uma pertinente espessura conceptual. Embora atravessando o campo da história da arte, não se reduz a uma abordagem estritamente histórica nem artística. Trata-se da própria especificidade da fotografia - ligada à sua constituição técnica e à possibilidade de nos aproximar da "objectualidade dos objectos" - pensada no seu desdobramento (FRIED, 2008).

Para lá desse aspecto mais centrado na dimensão artística, a fotografia, nos seus usos mais quotidianos e massificados (na sua relação com o arquivo, a fotografia familiar ou os media), instaurou também um conjunto de problemas que fazem parte das competências da estética - entendendo-se esta no seu sentido mais abrangente, náo redutível à filosofia da arte.

Não é este o lugar para explorar exaustivamente o modo como a questão da técnica permeia as reflexóes de Benjamin sobre a fotografia, mas poderemos acercar-nos de aspectos importantes, se nos focarmos em algumas passagens de "Pequena história da fotografia". Referindo-se à estreiteza dos debates que ocorreram no século XIX acerca do aparecimento da fotografia e da sua contraposição à pintura, Benjamin critica uma concepção de artista enquanto ser divino, regido pelas ordens superiores do seu génio. Cita uma passagem de um jornal alemão que se refere ao artista como aquele que, sem qualquer máquina, "tomado de inspiração celestial", seria capaz de reproduzir os traços divinos do homem, concluindo que se manifesta "[...] aqui, com todo o peso do seu estilo enfatuado, a ideia pequeno-burguesa da 'arte', a que é estranha 
qualquer consideração de ordem técnica e que receia ver chegar o seu fim com o aparecimento provocatório da nova técnica." (BENJAMIN, 2006c, p. 244). Perante a estreiteza dessa compreensão da arte e do artista, não é de estranhar que os debates sobre a natureza da fotografia tivessem sido toldados por uma série de preconceitos, os quais impediram a revelação da sua originalidade e das suas implicaçôes. É importante salientar que, para Benjamin, toda a arte tem uma componente técnica, pelo que as relaçôes entre as diversas formas artísticas não se regem por uma lógica de progresso ou de causalidade, mas sim por uma pesagem de ganhos e perdas. Esse ponto de vista não invalida, porém, uma ideia que ele tenta demonstrar várias vezes: existem elementos das novas formas artísticas (e suas técnicas correspondentes) que se encontram virtualmente contidas em formas precedentes. Em "A obra de arte na época da sua reprodutibilidade técnica” há uma referência explícita a essa ideia:

A história de cada forma de arte conhece épocas críticas em que esta forma aspira a efeitos que só se conseguem obter livremente quando se chega a um nível técnico diferente, isto é, a uma nova forma de arte. [...] o Dadaísmo tentou criar, com os meios da pintura (e da literatura), os efeitos que o público hoje em dia procura no cinema. (BENJAMIN, 2006a, p. 234-235, grifo do autor).

Neste sentido, poder-se-á dizer que a fotografia e o cinema, apesar de estarem necessariamente ligados à sua pré-história, às formas artísticas precedentes, trouxeram novos elementos, novas questóes, cujas ondas de radicalidade se têm propagado até aos nossos dias. Exemplar é também a passagem que contraria uma qualquer diferença de princípio entre técnica e magia; como decorre da análise de uma fotografia de Dauthendey, "[...] a mais exacta das técnicas é capaz de dar um valor mágico às suas realizaçóes, um valor que um quadro pintado nunca mais terá para nós." (BENJAMIN, 2006c, p. 246). Embora Benjamin se refira principalmente às fotografias das primeiras páginas do texto (de Dauthendey, Hill e Bloßfeldt), a diferença entre técnica e magia, enquanto variável totalmente histórica, deixa em aberto a possibilidade de outras variaçooes exemplares, observáveis em muitas das práticas fotográficas contemporâneas. A exploração da queimadura do real (a qual, em última instância, subverte o carácter de imagem da fotografia) e a exploração do inconsciente óptico (que revela e alarga o nosso mundo perceptivo) são características fundamentais em torno das quais se formam os valores estéticos ligados à fotografia. 
Posteriormente, remetendo a Atget e estabelecendo uma analogia com o pianista Busoni, Benjamin acaba por afirmar algo que aparenta ser óbvio para qualquer arte, mas que nem sempre recebe a devida atenção: aquilo que é decisivo para a fotografia é sempre a relação dos fotógrafos com a sua técnica (BENJAMIN, 2010b, p. 252-253). Quer nos primórdios da fotografia, quer no seu período de decadência (segundo a designação de Benjamin), as características fundamentais da fotografia são sempre vistas em função de uma relação com a técnica. Por exemplo, a aura das primeiras fotografias tinha como equivalente técnico a fraca qualidade das objectivas, que assim criavam zonas de sombra. A fraca sensibilidade das primeiras chapas e o consequente longo tempo de exposição conduziam os retratados a uma síntese de expressão que é táo característica dos primeiros retratos. Por outro lado, no período de decadência, surge uma tentativa de criar uma aura artificial, por intermédio do retoque (BENJAMIN, 2006c, p. 248-252).

Um último aspecto a marcar a importância da fotografia no pensamento de Benjamin prende-se com a hipótese, algo especulativa, de que esse mesmo pensamento tem uma dimensão fotográfica. Essa constatação tornar-se-á porventura menos estranha, se lançarmos um olhar sobre o texto "O autor como produtor" e à exigência, de teor revolucionário, que aí é feita aos escritores e fotógrafos do seu tempo: que ambos superem as barreiras entre texto e imagem - as barreiras das competências levantadas pelo próprio sistema de produção -, que os fotógrafos sejam capazes de dar uma legenda às suas fotografias, resgatando-as do desgaste pela moda, e que os escritores sejam capazes de fazer fotografia (BENJAMIN, 2006b, p. 284). Portanto, não só Benjamin foi um atento observador da fotografia, mergulhando nos problemas teóricos por ela levantados e convivendo de perto com imagens e fotógrafos, como também o seu próprio pensamento ter-se-á impregnado de mecanismos fotográficos - numa espécie de contaminação que se expande desde as técnicas até aos modos de pensamento, passando pelo próprio exercício da escrita. Dito de outra forma: há elementos de fundo do seu pensamento, nomeadamente a noção de imagem dialéctica, que podem ser aproximados de mecanismos fotográficos. Essa aproximação manifesta-se, desde logo, pelo elemento da descontinuidade, da interrupção do contínuo temporal, que tão importante é no contexto de Das Passagen-Werk e que aparece condensada, de um ponto de vista mais programático, nas teses de "Sobre o Conceito de História". Este é um dos aspectos decisivos para a aproximação entre fotografia e história desenvolvida por Eduardo Cadava (1997, p. 60): 
Benjamin descreve a sua posição relativamente à história e à historiografia contra as posições predominantes, e fá-lo afirmando um movimento de interrupçáo que suspende o continuum do tempo. Ao reter os vestígios do passado e do futuro - um passado e futuro que ela todavia transforma - a fotografia mantém a presença do movimento, as pulsaçóes cujo ritmo marca a sobrevivência daquilo que foi compreendido no interior do movimento que ela petrifica. Somente quando o olhar de Medusa do historiador materialista ou da câmara tiver momentaneamente trespassado [transfixed] a história, pode a história aparecer como história no seu desaparecimento. No interior desta condensação de passado e presente, o tempo já não deve ser entendido como contínuo e linear, mas como espacial, um espaço imagético ao qual Benjamin chama "constelação" ou "mónada".

A compreensão da espacialidade imagética do tempo histórico é como que o complemento da crítica ao positivismo e ao ideal de progresso. Neste caso, contudo, não se trata apenas da constatação da historicidade e do carácter destrutivo da técnica: trata-se também dos procedimentos específicos da própria técnica fotográfica. A fixação da imagem, elemento básico de qualquer fotografia, pode então ser entendida como metáfora e, em última instância, como conceito histórico-temporal.

\section{QUATRO NOTAS SOBRE A TRANSFORMAÇÃO DOS VALORES ESTÉTICOS}

\subsection{Historicidade DA PERCEPÇÃo}

Há uma passagem famosa e muito citada do texto "A obra de arte na época da sua reprodutibilidade técnica", a qual se refere ao modo como a percepção humana é historicamente condicionada. $\mathrm{Na}$ terceira versão do ensaio, lê-se:

Adentro de grandes periodos históricos transforma-se todo o modo de existência das sociedades humanas, e com ele o seu modo de percepção. $\mathrm{O}$ modo como se organiza a percepção humana - o meio por que se realiza - não é apenas condicionado pela natureza, mas também pela história. (BENJAMIN, 2006a, p. 212, grifo do autor).

É importante ressaltar que, nesta passagem, não está em causa um fatalismo histórico ou tecnológico que reduza as teorizaçóes sobre a percepção a um primado absoluto da mediação. $\mathrm{O}$ reconhecimento de 
que a nossa percepção é - sempre foi - mediada, não deve conduzir a uma reificação das instâncias mediadoras. Técnica e transformaçôes sociais são elementos importantes, embora não exclusivos, na compreensão dos modos de percepção, compreensão que deve afastar-se de uma lógica de causalidade. Num sentido bastante diferente, Benjamin propóe-se pensar as mudanças da percepção, partindo sempre já de um terreno no qual diversos estratos estáo em comunicação, sendo prestada uma particular atenção às transformações sociais e, nesse texto em particular, às diversas implicaçóes da possibilidade de reproduzir, através das novas técnicas, a existência única de cada situação ou obra de arte. Como vimos no texto sobre Eduard Fuchs, a técnica, analisada sob o ponto de vista histórico, é exactamente um dos domínios que possibilita contornar a falsa oposição entre ciências da natureza e ciências do espírito, pondo em causa a própria validade das leituras cronológicas dos fenómenos artísticos.

O fenómeno da "decadência da aura" permite acentuar os elementos que, embora ligados a objetos artísticos concretos, não são pensáveis sem a assunção da constituição mediada - histórica e tecnicamente - da nossa percepção. A experiência da aura, igualmente uma experiência do nosso olhar ou daqueles que em nós repousam, é um bom exemplo dessa forma de pensar a percepção em função de um fundo histórico, irredutível a sentenças finais, e que constitui um fiel de balança na pesagem dos valores estéticos.

A articulação entre mediação técnica e história é um dos momentos importantes da abertura de um campo transdisciplinar que vai desde a filosofia às ciências da comunicação. Ainda que de um ponto de vista diferente do de Benjamin, os trabalhos de Marshall MacLuhan (e.g. A Galáxia de Gutenberg) ou de Vilém Flusser (e.g. Um Ensaio sobre a Fotografia. Para uma Filosofia da Técnica) também exploram a relação profunda entre os modos sensitivos e os meios de comunicação que condicionam as vivências sociais e históricas. Para Flusser, a fotografia tem um estatuto paradigmático (em função de conceitos como os de aparelho ou caixa negra), constituindo um modelo para pensar a técnica e, mais especificamente, as transformaçôes introduzidas pelas imagens técnicas. Por um lado, a sua proposta insere-se numa linhagem benjaminiana, nomeadamente no que toca à compreensão do efeito de ruptura introduzido pelas imagens técnicas; por outro lado, a sua abordagem revela (sem deixar de apontar linhas de fuga) uma visão bem mais céptica relativamente ao carácter emancipador da fotografia. Curiosamente, e embora não o assuma, Flusser 
também prolonga intuições benjaminianas (que analisaremos adiante), ao identificar a abertura de uma dimensão de jogo nas relaçôes que os fotógrafos estabelecem com o aparelho. Essa dimensão, implicando a liberdade humana, tem igualmente um carácter que não deixa de ser utópico. Não se trata, porém, de um jogo redutível a uma dimensão lúdica e descomprometida; pelo contrário, trata-se de um jogo que, aceitando a mediação técnica e histórica da experiência humana, aceita também, dentro de um determinado espaço de manobra (em alemão: Spielraum, termo utilizado por Benjamin), o comprometimento com a transformação do modo de existência das sociedades (FLUSSER, 1998).

\subsection{A DIMENSÁ̃ POLÍTICA DA ARTE}

É também incontornável a forma como Benjamin introduziu a dimensão política nas suas reflexóes sobre arte. Em "A obra de arte na época da sua reprodutibilidade técnica", as teses sobre a perda do valor de culto das obras de arte e o consequente acréscimo do valor de exposição, teses directamente ligadas à dissolução do critério da autenticidade, desembocam na constatação de uma nova função social da arte: a política (BENJAMIN, 2006a, cap. IVV). Na parte final desse mesmo texto, as questôes políticas são colocadas de um modo mais aguçado. Não podendo ser consideradas ideológicas, as análises visam, contudo, uma demarcação entre duas perspectivas, as quais, ao tempo do ensaio, marcavam claramente uma cisão política. Assim, as teses finais desembocam na famosa oposição entre a esteticização da política por intermédio do fascismo e, como reacção à primeira, a politização da arte por intermédio do comunismo (BENJAMIN, 2006a, p. 239-241).

Menos examinada é a maneira como a dimensão política está enraizada em aspectos técnicos que se situam aquém da própria reprodutibilidade técnica das obras de arte ou da sua relação com as massas. O significado político da relação entre técnica e arte, ou entre técnica e fotografia, brota dos próprios processos do modo de registo. Essa ideia constitui o pano de fundo de vários textos de Benjamin, mas encontra uma formulação contundente na secção dedicada à fotografia de Das Passagen-Werk. Já perto do final das entradas identificadas com a letra $Y$, são apresentadas algumas citaçôes que dão conta de aspectos relativos às inovaçóes técnicas que preparam e antecipam a chegada da fotografia. Após uma longa citação de Dolf Sternberger, atinente à maneira como o panorama inscreve o factor temporal na experiência do espectador por 
intermédio da fabricação das horas do dia, a próxima entrada - um comentário e não uma citação - salienta o seguinte:

A entrada do momento temporal no panorama é assegurada pela sequência das horas do dia (com os truques de iluminação que são bem conhecidos). $\mathrm{O}$ panorama transcende assim a pintura e antecipa a fotografia. Em virtude da sua constituição técnica, a fotografia, diferentemente da pintura, pode e deve ser subordinada a um intervalo de tempo determinado e contínuo (tempo de exposição). Nesta capacidade de precisão cronológica encontra-se já contido, in nuce, o seu significado político. (BENJAMIN, 1991, p. 844).

Seguindo o contexto e os pressupostos deste trecho, podemos afirmar que a irrupçáo da fotografia marca algo de inaudito; isto é, por mais que o tempo e a cultura ocidental estivessem maduros e antecipassem o seu aparecimento, por mais que se possa pensar a fotografia como uma espécie de consumação de um desejo antropológico de cariz realista, o acontecimento fotográfico marca qualquer coisa de revolucionário. Já não se trata de pintura, já não se trata de uma luz fabricada, como nos panoramas, mas da própria luz que se inscreve no material fotossensível, num segmento de tempo contínuo e bem definido. Esse momento de contacto, o qual se dá no tempo de exposição, tem um conteúdo político embrionário, pois desde logo a sua constituição técnica abre um campo de forças disruptivas, de potencialidades - que é também um espaço de manobra e de jogo.

Em "Pequena história da fotografia", e remetendo a uma fotografia de David Octavius Hill, encontramos uma descrição que encerra a consciência aguda de que o retrato fotográfico inaugura um novo espaço, irredutível às categorias artísticas do passado:

[...] na fotografia deparamos com algo de novo e especial: naquela peixeira de New Haven, de olhos postos no chão com um pudor indiferente e sedutor, permanece algo que não se esgota como testemunho da arte do fotógrafo Hill, qualquer coisa que não se pode reduzir ao silêncio, que reclama insistentemente o nome daquela mulher que viveu um dia, que continua a ser real hoje e nunca quererá ser reduzida a "arte". (BENJAMIN, 2006c, p. 246).

Face à mudez constitutiva da fotografia (que também Roland Barthes não deixou de assinalar), esse "algo de novo e especial" que irrompe com a 
materialidade do real, que se inscreve na imagem e "reclama insistentemente o nome" dos retratados, obriga-nos a reconsiderar o que está contido, de modo embrionário, na mudez.

Outras dimensôes políticas da fotografia podem ser encontradas no "Exposé", de 1935, de Das Passagen-Werk. Antes de mais, pela revolução iniciada pelos panoramas, a qual pressupóe uma mudança nas relaçóes entre arte e técnica; ao mesmo tempo, os panoramas fazem parte de uma nova atitude perante a vida, que implica uma alteração da relação entre o campo e a cidade: no panorama a cidade abre-se, tornando-se paisagem. Todavia, com o aparecimento do daguerreótipo, outras transformaçóes fundamentais têm lugar. Perante as novas realidades tecnológicas e sociais, a tendência subjectiva nas artes pictóricas e gráficas começa a ser colocada em questão. Benjamin destaca o caso de Nadar, não se referindo aos seus belíssimos retratos, mas sim às suas fotografias dos esgotos de Paris. Nelas, Nadar mostra a sua superioridade em relação aos seus colegas contemporâneos: o trabalho fotográfico revela-se capaz de fazer descobertas, apresentando aquilo que antes estava escondido. Pode então sustentar-se que também nesse sentido a fotografia produz - ou é uma parte importante na formaçáo de - um novo espaço social e político. Benjamin refere-se ainda a um artigo publicado por Wiertz, segundo o qual a fotografia teria como tarefa a "iluminação filosófica" da pintura. Essa iluminação deve ser entendida no sentido político. Wiertz teria sido o primeiro a requerer, se náo mesmo a antecipar, o uso da montagem fotográfica como forma de agitação política (BENJAMIN, 1991, p. 48-49).

Queimadura do real no tempo de exposição como significado político in nuce; participação da fotografia num novo espaço sociopolítico, por intermédio da sua capacidade de fazer descobertas; montagem fotográfica como forma de agitação política. Podem resumir-se assim alguns dos traços que, nascendo da própria constituição técnica da fotografia, tecem a sua dimensão política.

\subsection{Fotografia(s) E MEMÓRIa(s)}

Pode dizer-se que a fotografia (também enquanto objecto teórico) ocupa um território intermédio, furtando-se a oposiçóes conceptuais rígidas. As fotografias são entidades paradoxais, tocadas pela luz das coisas, mas sujeitas às mais variadas manipulaçóes. Partindo dessa constatação geral, vemos que a fotografia é uma técnica que, na sua aparente simplicidade e no seu uso 
massificado, complexifica as próprias categorias que utilizamos para pensar. A relação entre fotografia e memória padece dessa aparente simplicidade e, portanto, de uma enorme complexidade. Por um lado, tendo sido tocadas por uma realidade que de nós se distancia, pelo transcorrer do tempo, as fotografias não deixam de realizar uma aproximação brusca ao passado, conduzindo a nossa consciência a uma paradoxal relação entre duas ordens temporais, a qual parece implicar necessariamente uma forma de memória. Por outro lado, face à polissemia da palavra memória e face à própria diversidade de usos fotográficos, parece difícil dar conta dos termos exactos nos quais se joga essa relação.

Numa definição de senso comum, próxima da constituição técnica da fotografia, esta é uma fixação espácio-temporal, ou seja, uma forma de registar um determinado momento que entra na memória individual ou colectiva; os álbuns e arquivos, enquanto dispositivos de memória, são assim um prolongamento desse elemento constitutivo.

Numa outra ordem de ideias, a fotografia constitui uma mnemotécnica. O ser humano, enquanto ser técnico, desenvolveu-se em função dessas formas de exteriorização que constituem a memória. Nesse sentido, a fotografia envolve também a história cultural e as formas de experiência abertas pelas novas técnicas, que não se oferecem nem como uma continuidade linear, nem como uma ruptura absoluta. Perceber o que a técnica fotográfica e as fotografias fazem à experiência humana é também fazer as contas entre a memória e o esquecimento, entre a abertura de novas possibilidades de experiência e a destruição de anteriores. ${ }^{4}$

Existem várias analogias entre memória e fotografia. É comum tratarmos da fotografia como modelo de funcionamento da nossa memória, nomeadamente a partir de noçóes ligadas ao registo fiel e detalhado (a expressão "memória fotográfica”), ao arquivo ou ao álbum. Mas essas analogias são limitadas: entre outros, a nossa memória é constituída por uma série de elementos linguísticos, perceptivos ou inconscientes que esses modelos têm

\footnotetext{
${ }^{4}$ Talvez aquilo que cada técnica nova introduz na nossa experiência possa ser interpretado segundo o conceito de origem, tal como é desenvolvido por Benjamin, no "Prólogo" a Origem do drama barroco alemão: uma reconstituiçâo incompleta, o surgimento de algo novo que conserva sempre os vestígios das coisas passadas. Portanto, num domínio mais amplo, essa mnemotécnica instaurada pela técnica fotográfica, com modos muito específicos de sentir e viver o tempo e a realidade, desempenha um papel singular na história das técnicas (de reprodução), sem, contudo, deixar de fazer ressoar os vestígios do passado.
} 
dificuldade em abarcar. Contudo, existem dois aspectos interessantes nas analogias: primeiro, a ideia de cesura, de interrupção, a qual tem uma relação com a experiência do choque e que permite o cruzamento entre duas ordens espácio-temporais, o presente e o passado; segundo, a questão da montagem, que abre para uma perspectiva acronológica, sensível aos saltos temporais, às operaçóes do inconsciente, à descoberta de novas correspondências. Vemos, por exemplo, a importância que as reproduçóes fotográficas têm no Atlas Mnemosyne de Aby Warburg, parecendo este responder a uma possibilidade aberta pela própria técnica fotográfica.

De referir ainda a articulação entre fotografia, memória e afecto, exemplarmente mostrada por Roland Barthes, em A Câmara Clara. Embora, nessa obra, a relaçáo com o tempo, com o "isto foi", desponte como uma das características fundamentais da fotografia, toda ela está mergulhada num fundo afectivo. Esse fundo é assumido pelo próprio autor, o qual tece também uma crítica à concepção fenomenológica da imagem e lança outras possibilidades de compreensão da fotografia; isto é particularmente agudo nas análises que decorrem da fotografia do "Jardim de Inverno" (BARTHES, 1980).

Mas foquemo-nos agora em Benjamin.

No texto "Franz Kafka, no décimo aniversário da sua morte", Benjamin faz uma leitura da obra de Kafka que, à data, se mostrava original e propunha novos caminhos de interpretação. Um desses caminhos desenvolve a ideia de que a obra de Kafka constitui uma revelação de acontecimentos, de gestos no Teatro do Mundo. Neste sentido, ela poria em cena um código de gestos que a priori não possuem um claro significado simbólico, constituindo antes interrogaçóes cujo significado se expressaria através de "[...] relaçóes e ordenaçóes experimentais [Versuchsanordnungen] sempre novas. O teatro é a sede natural destas ordenaçôes experimentais.” (BENJAMIN, 1991, p. 418). ${ }^{5}$ A obra de Kafka seria, assim, um ensaio sobre os gestos, a procura de um gesto perdido.

Saliento ainda dois aspectos importantes desse texto.

\footnotetext{
${ }^{5} \mathrm{O}$ termo Versuchsanordnung, que também poderia ser traduzido por ensaio, encontra-se em pelo menos mais dois textos de Benjamin: em "O que é o teatro épico?" e na segunda versão do ensaio "A obra de arte...” Neste último ensaio, o termo serve para caracterizar a segunda técnica, aproximando-a do jogo. Sigo aqui a tradução proposta por Luciano Gatti (2009, p. 174), cujo livro Constelaçóes. Crítica e verdade em Benjamin e Adorno desenvolve um exame detalhado da questão do gesto (nas suas articulaçóes com as temáticas do corpo e do materialismo), nas interpretaçôes que Benjamin faz de Brecht e Kafka.
} 
O primeiro diz respeito a uma concepção do corpo - do nosso próprio corpo - como a maior fonte de estranheza. Referindo-se a $O$ Castelo, Benjamin assinala: "Tal como $\mathrm{K}$. vive na aldeia junto à colina do castelo, assim também o homem de hoje vive no seu corpo; ele escapa-lhe, é-lhe hostil.” (BENJAMIN, 1991, p. 424). Essa estranheza tem uma relação profunda com os animais, os depositários daquilo que se esqueceu, aqueles que conservam a angústia e, ainda assim, mais se dedicam à reflexão. Esta ideia surge no contexto de uma análise da luta contra o esquecimento. Porém, aquilo que foi esquecido nunca é puramente individual, há algo de cósmico (e não necessariamente religioso) nos gestos incompreensíveis. Daí eles parecerem brotar de um mundo estranho, pré-histórico - a fonte de onde emanam os escritos de Kafka (BENJAMIN, 1991, p. 430-431).

O segundo aspecto diz ainda respeito ao esquecimento e à estranheza. A personagem principal de América, Karl Rossmann (personagem que pela primeira vez, num romance de Kafka, é apresentada com um nome e não com uma inicial), acaba por dirigir-se ao teatro natural de Oklahoma, o teatro onde todos os actores parecem capazes de representar o seu papel, que no fundo é a sua vida redimida. Mas existe uma personagem que ainda não o conseguiu. É o estudante de gestos insondáveis. Para Benjamin, ele encarna a necessidade do estudo como tentativa de encontrar a redenção, o gesto perdido. Para explicitar essa ideia, Benjamin estabelece uma analogia entre quem se procura encontrar por intermédio das técnicas de reprodução (cinema e gramofone, no caso) e a situação de Kafka. O cinema e o gramofone foram inventados numa época de grande alienação entre os homens, de relaçóes incomensuravelmente mediadas:

No cinema, o homem não reconhece o seu próprio modo de andar, no gramofone, não reconhece a própria voz. Há experiências que o provam. A situação da cobaia nessas experiências é a situação de Kafka. É ela que o conduz ao estudo. Talvez aí se depare com fragmentos da própria existência, os quais se encontram ainda em conexão com o papel. (BENJAMIN, 1991, p. 436$){ }^{6}$

${ }^{6}$ Em "A obra de arte na época da sua reprodutibilidade técnica", Benjamin escreve algo que complementa a passagem do texto sobre Kafka: "A sensaçáo de estranheza do intérprete diante da aparelhagem, tal como Pirandello a descreve, é por natureza do mesmo género que a sensação de estranheza do homem perante a sua imagem no espelho. Agora, porém, a imagem formada no espelho pode separar-se dele, torna-se transportável." (BENJAMIN, 2006a, p. 225). 
Podemos então afirmar que, paradoxalmente, ao aumentarem o campo da memória, as técnicas de registo também ampliam o problema do autorreconhecimento, da estranheza em relação à nossa própria identidade, conduzindo-nos à inquietude do estudo. Aquilo que Benjamin náo diz, mas nós podemos acrescentar, é que também a fotografia contemporânea tem um papel fundamental nessa equação entre estranheza, esquecimento e memória, constituindo um campo privilegiado (dentro e fora do meio artístico) para o estudo dos gestos no Teatro do Mundo. Vejam-se, por exemplo, os casos de Cindy Sherman ou de John Coplans, os quais constituem, cada um a seu modo, casos de estudo acerca dos gestos, da sua relação com o corpo e a memória. Portanto, existe um potencial redentor relativamente aos destroços deixados pelas técnicas de registo. Por outras palavras, elas contêm uma promessa que o próprio tempo tem vindo a revelar. Para Rosalind Krauss num texto onde manifestamente procura reler Benjamin, com o intuito de pensar a especificidade do medium fotográfico - essa promessa está associada aos poderes cognitivos da infância (KRAUSS, 2006). Uma passagem de "Sobre alguns motivos na obra de Baudelaire" refere-se à fotografia e outras aparelhagens em termos de um alargamento da mémoire voluntaire que implica, por outro lado, uma "decadência da aura" ao nível dos objectos que revelam marcas de uso e ao nível da aura que se acumula em torno das próprias imagens da mémoire involuntaire. "Os dispositivos das máquinas fotográficas e aparelhagens semelhantes que vieram depois alargam o alcance da mémoire voluntaire, a aparelhagem permite a qualquer momento fixar um acontecimento em imagem [Bild] e som." (BENJAMIN, 2006a, p. 140). Por conseguinte, para lá de todas as perdas inerentes à aura, a memória voluntária da fotografia tem as suas potencialidades, ampliando o nosso contacto com camadas gestuais e expressivas, ampliando o nosso inconsciente óptico.

Se é verdade que, genericamente falando, o gesto de pegar no isqueiro ou na colher nos é familiar, já pouco ou nada sabemos do que de facto se passa entre a mão e o metal, para já não falar das oscilaçóes que esse processo acusa, segundo a disposição em que estamos. Aqui intervém a câmara com os seus meios auxiliares, plongés e contreplongés, interrupções e imobilizações, retardador e acelerador, ampliação e redução. É ela que nos inicia no inconsciente óptico, tal como a psicanálise no inconsciente pulsional. (BENJAMIN, 2006a, p. 233-234).

No início do capítulo a que pertence esta citação, Benjamin começa por caracterizar o cinema náo só pelo modo como o homem se apresenta perante 
a aparelhagem, mas também pela maneira como, através dessa aparelhagem, ele representa o mundo circundante. Esse enriquecimento da percepção, o qual pode ser explicado numa analogia com a teoria freudiana, decorre da possibilidade de isolar e tornar analisáveis aquelas coisas que antes navegavam inconscientemente na corrente da percepção. A relação entre a psicologia das performances e o cinema dá-se pelo modo como este permite avaliar, analisar as acções, facto que, por sua vez, promove uma nova articulação entre arte e ciência. No fundo, e regressando ao texto de Kafka, pode asseverar-se que o cinema constitui então um espaço de análise, de ordenaçôes experimentais, de estudo, de performance, de exercício sensorial e perceptivo - sobre a forma como o homem se apresenta à câmara, mas também sobre o modo como, através da câmara, o homem representa o mundo circundante. E aquilo que Benjamin tinha esperança de ver consumar-se, por meio do cinema, fora progressivamente antecipado pela fotografia, à medida que esta foi povoando o nosso mundo perceptivo com imagens inconscientes, construindo memória.

\subsection{SEgUNDA TÉCNICA E JOGO}

No quadro da segunda versão do ensaio "A obra de arte na época da sua reprodutibilidade técnica", e referindo-se ao cinema, Benjamin tece alguns comentários relativos ao que ele chama de segunda técnica, onde se dá uma reformulação dos aspectos miméticos da arte e da própria relação entre aparência (Schein) e jogo (Spiel), com uma acentuação do segundo polo. É de salientar que, à excepção de trechos da versão francesa, essas consideraçóes não se encontram nas outras versóes do texto. No capítulo VI, a primeira técnica é associada ao valor de culto e à dimensão mágica. A primeira técnica faria o máximo uso possível dos seres humanos, ao passo que um dos traços fundamentais da segunda técnica seria exactamente uma participação mínima dos seres humanos. É no distanciamento em relação à natureza que se situa a origem da segunda técnica, distanciamento que também pode ser denominado de jogo. Mais do que dominar a natureza, a segunda técnica procura uma interacçáo, um jogo-conjunto (Zusammenspiel) entre a natureza e a humanidade (BENJAMIN, 2012, p. 35-45). Nesse sentido, a função social primeira da arte seria o exercício dessa interacção. Na nota 10 do capítulo XI, Benjamin desenvolve essa questão, sobretudo a passagem do domínio da bela aparência para o do jogo, passagem que acompanha o aparecimento da segunda técnica. Ora, é nesse quadro que ele introduz a mímesis enquanto polaridade que, mais do que opor aparência e jogo de forma irredutível, cria entre ambos 
uma tensão. Essa polaridade é importante, porque tem um papel histórico e assim ilumina a passagem da primeira para a segunda técnica: aquilo que se perde em aparência ganha-se em jogo, em espaço de jogo/espaço de manobra (Spielraum). Por outras palavras, trata-se de uma transformação profunda dos próprios valores estéticos. Esse processo ter-se-ia iniciado com a fotografia, agudizando-se com o cinema (BENJAMIN, 2012, p. 72-76).

\section{CONCLUSÃo - OU AFIRMAÇÁO DAS AMBIGUIDADES}

Perante a complexidade do pensamento de Walter Benjamin, e ao contrário do que propõem certas leituras sedimentadas, convém não esquecer o que aparece em estado nascente, em diversos textos e fragmentos. De salientar, por exemplo, uma entrada de Das Passagen-Werk, na qual, por intermédio da infância, o mundo da técnica moderna é articulado com o mundo arcaico dos símbolos da mitologia:

Só um observador superficial pode negar que haja correspondências entre o mundo da técnica moderna e o mundo arcaico dos símbolos da mitologia. Inicialmente, sem dúvida, a nova técnica parece ser somente isso. Mas logo com a primeira rememoraçáo de infância ela muda os seus traços. Cada infância realiza qualquer coisa de grande, de insubstituível para a humanidade. Pelo seu interesse nos fenómenos técnicos, pela curiosidade relativa a todo o tipo de invençôes e de máquinas, cada infância liga os avanços da técnica aos antigos mundos dos símbolos. Não há nada na natureza que à partida esteja excluído dessa ligação. Contudo ela não se forma na aura da novidade, mas sim na do hábito. Em recordação, infância e sonho. - Despertar - [N 2a, 1]. (BENJAMIN, 1991, p. 576).

No contexto de "A obra de arte na época da sua reprodutibilidade técnica”, o hábito aparece ligado à questão da recepção táctil, aquela que substitui a recepçáo óptica da contemplação, segundo os desafios colocados pelo efeito de choque. Já nessa ocorrência, ele está associado a uma aura que se opóe à da novidade e que implica a rememoração, a infância e o sonho. Portanto, as análises relativas à reprodutibilidade técnica das obras de arte estão longe de esgotar o espectro de relaçóes entre as novidades técnicas, a arte, a experiência humana ou a natureza. Na verdade, deve falar-se de diversos níveis de análise no pensamento de Benjamin sobre a técnica, diversidade que, mais do que originar contradiçôes, estabelece um campo de tensóes, pressupondo a lúcida constatação de que a técnica se coloca, simultaneamente, quer do lado 
da destruição das formas tradicionais da vida e da experiência (Erfahrung), acentuando a experiência vivida (Erlebnis) do choque, quer do lado dessa potência redentora que toda a criança tem nas mãos. A capacidade de "ligar os avanços da técnica aos antigos mundos dos símbolos" pressupóe, portanto, o reconhecimento do poder dos traços que constituem a própria figura da infância - os quais, se assim o podemos dizer, podem ser rememorados, exercitados ao longo da vida e em diferentes contextos tecnológicos, acentuando uma dimensão do presente que náo se esgota na novidade. Sendo necessariamente transversal à experiência humana, esse poder de cada infância encontra na arte um domínio privilegiado de actuação.

A noção de jogo, em toda a sua amplitude dramática, vital, lúdica, política, tem aqui um dos seus substratos históricos mais importantes. Contudo, a vertente lúdico-experimental para que Benjamin aponta, em muitos dos seus textos, não sugere um "reencantamento do mundo". A articulação entre a experiência mimética das crianças e as experimentaçôes da vanguarda está vinculada a uma noção de "[...] acção política que não visa a transformação do mundo segundo normas prefixadas, mas a partir de exercícios e tentativas nos quais a experiência humana - tanto espiritual e inteligível como sensível e corporal - assume outras formas." (GAGNEBIN, 2014, p. 175).

A ligação entre os avanços da técnica e os antigos mundos da mitologia pressupõe também uma dimensão histórico-temporal particular, nos antípodas da ideia de progresso ou de causalidade, o que vai ao encontro de uma exigência referida inicialmente: a procura de uma compreensão da técnica capaz de atender, quer aos seus momentos construtivos, quer aos seus momentos destrutivos, e que tenha por base a interrupção do contínuo histórico. Por conseguinte, não se trata de celebrar nem de denunciar a presença desses símbolos da mitologia, mas sim de tomar consciência deles e das forças ambíguas que se lhes associam. Despertar não é tanto um gesto de rejeição de fantasmagorias quanto de constatação de um processo dialéctico incessante. Uma passagem do "Exposé de 1935”, referente ao carácter moderno da poesia de Baudelaire, diz algo de revelador quanto à ambiguidade dos processos dialécticos:

[...] mas precisamente a modernidade está sempre a citar a história originária (Urgeschichte). Neste caso, isso acontece através da ambiguidade a que se prestam as relaçóes e os produtos sociais desta época. A ambiguidade é a apariçáo figurativa da dialéctica, a lei da dialéctica em suspensão. Esta suspensão é utopia, e a imagem dialéctica é também imagem onírica. Tal imagem é apresentada pela pura e simples mercadoria: como fetiche. 
Tal imagem é apresentada pelas passagens, que tanto são casa como rua. Tal imagem é apresentada pela prostituta, ao mesmo tempo vendedora e mercadoria. (BENJAMIN, 1991, p. 55).

Estas últimas consideraçóes servem para expandir o alcance das notas esboçadas no presente texto. Mais do que descrever traços uniformes na estética contemporânea, identificáveis em estado puro, elas procuraram sobretudo desenhar um campo de possibilidades aberto pelo "questionamento sobre a técnica”, campo que já há muito se encontra num movimento produtivo, carregado de tensôes e ambiguidades. Historicidade da percepção, dimensão política, memória e jogo são, assim, traços que se mesclam entre si e com outros que aqui não foram abordados. Constituindo eixos em torno dos quais vemos aglomerarem-se um sem-número de fenómenos estéticos, são também valores que norteiam a prática artística e o discurso crítico.

CONCEIÇÃO, Nélio Rodrigues. From the genius to play: the role of technology in the transformation of aesthetic values in Walter Benjamin. Tans/form/ação, Marília, v. 40, n. 1, p. 87-108, Jan./Mar., 2017.

ABSTRACT: Analyzing the role played by the question of technology in Walter Benjamin's thought, this article delves into the transformation of aesthetic values in modernity. The technologies of reproduction and recording invented during the 19th and 20th centuries, such as photography and cinema, led to a reformulation of the relationship between art, technology, and history, which Benjamin examined in various ways. However, we do not find in his texts a philosophy of technology with well-defined principles. Therefore, this article aims at establishing a constellation of themes emerging from his texts, that allows us to clarify the way technology promotes the transformation and creation of aesthetic values. These values are here understood as axes around which the production and the critique of aesthetic phenomena occur. Photography, as a turning point that was incisively studied by the author, is the leading thread in the different readings of his work. The historicity of perception; the political dimension of art; its relation with memory; the element of play: these are the four axes around which a clarification and, whenever possible, an expansion, of Benjamin's ideas are discussed.

KeYwords: Technology. History. Politics. Memory. Play

\section{REFERÊNCIAS}

AGAMBEN, G. Infância e história: destruição da experiência e origem da história. Belo Horizonte: Editora da UFMG, 2014.

BARTHES, R. La Chambre Claire : note sur la photographie. Paris: Cahiers du Cinéma ; Gallimard/Seuil, 1980. 
BENJAMIN, W. Das passagen-Werk. In: Gesammelte schriften. Band V. Frankfurt am Main: Suhrkamp, 1991a.

. Franz Kafka: zur zehnten Wiederkehr seines Todestages. In: Gesammelte schriften. Frankfurt am Main: Suhrkamp, 1991b [1934], p. 409-438. II.2.

. Gesammelte schriften. Frankfurt am Main: Suhrkamp, 1991c [1972-1989]. 7 v.

. A obra de arte na época da sua possibilidade de reprodução técnica (terceira versão). In: . A modernidade. 3. ed. Tradução João Barreto. Lisboa: Assírio e Alvim, 2006a [1955]. p. 207-241.

. O autor como produtor. In: . A modernidade. 3. ed. Tradução João

Barreto. Lisboa: Assírio e Alvim, 2006b [1934]. p. 271-293.

- Pequena história da fotografia. In: . A modernidade. 3. ed. Tradução João

Barreto . Lisboa: Assírio e Alvim, 2006c [1931].

. Sobre alguns motivos na obra de Baudelaire. In: . A modernidade. 3. ed.

Traduçáo João Barreto. Lisboa: Assírio e Alvim, 2006d [1940].

. Eduard Fuchs, coleccionador e historiador In: O Anjo da História. Lisboa: Assírio e Alvim, 2010 [1937].

. A obra de arte na época de sua reprodutibilidade técnica. 2. versão. Porto Alegre: Zouk, 2014 [1989].

CADAVA, E. Words of light: theses on the photography of history. New Jersey: Princeton University Press, 1997.

FLUSSER, V. Ensaio sobre a fotografia: para uma filosofia da técnica. Lisboa: Relógio d'Água, 1998 [1985].

FRIED, M. Why photography matters as art as never before. New Haven; London: Yale University Press, 2008.

GAGNEBIN, J. M. Limiar, aura e rememoração: ensaios sobre Walter Benjamin. São Paulo: Editora 34, 2014.

GATTI, L. Constelações: crítica e verdade em Benjamin e Adorno. São Paulo: Loyola, 2009.

KRAUSS, R. Reinventar o medium: introdução à fotografia. In: NICOLAU, R. (Ed.). A fotografia na arte: de ferramenta a paradigma. Porto: Fundação de Serralves; Jornal Público, 2006. p. 152-162.

WEIGEL, S. Walter Benjamin: images, the creaturely, and the Holy. Stanford: Stanford University Press, 2013 [2008].

Recebido em 02/08/2016

Aceito em 19/12/2016 